\title{
Hypothyroidism and Hyperprolactinemia as a Cause of Primary Infertility: A Single Center Study
}

\author{
Nihida Akhter ${ }^{1}$, Asma Khanday ${ }^{2}$, Irfan N Mir ${ }^{3}$
}

\begin{abstract}
Introduction: Infertility is a common condition, with important medical economic and psychological implications. We have observed a surge in cases of primary infertility in our OPD of late. Hypothyroidism and hyperprolactinemia have been implicated as a cause of primary infertility. Materials and methods: We conducted a prospective cross-sectional study in our hospital, Government Medical College, on an OPD basis, between May 2017 and January 2019, to check for hypothyroidism and hyperprolactinemia as a cause of primary infertility among females, after ruling out other common implicated factors that may be the cause of infertility. We labeled the study group as group I and the control group as group II.

Results: The mean age of patients in group I was 26.21 years, and that in group II was 25.63 years, respectively. The average time since marriage in group I was found to be 1.67 years and that in group II was 1.78 years, respectively. The rural-urban ratio of patients in group I was 23:27 and that in group II was 34:16. The mean TSH level in group I was found to be $7.11 \pm 1.91$ and that in group II was found to be $3.28 \pm 2.11$. The mean levels of serum prolactin in group I were $41.62 \pm 20.02$ and that in group II were $22.36 \pm 15.61$, respectively. There was a high prevalence of hypothyroidism and hyperprolactinemia in group I when compared with group II.

Conclusion: This study showed significantly higher prolactin and TSH levels among the primary infertile female patients. Therefore, for proper management of infertile cases, it may be necessary to look for thyroid dysfunction and treat it accordingly.

Keywords: Hyperprolactinemia, Primary infertility, Thyroid-stimulating hormone.

International Journal of Infertility and Fetal Medicine (2021): 10.5005/jp-journals-10016-1222
\end{abstract}

\section{INTRODUCTION}

The prevalence of infertility is estimated to be between $12 \%$ and $14 \%$. It thus represents a common condition, with important medical, economic, and psychological implications. ${ }^{1}$

Infertility is defined as an inability to conceive even after 1 year of unprotected intercourse or the inability to carry a child to term. ${ }^{2}$ Primary infertility is a term that is meant for a couple who have never achieved a pregnancy. ${ }^{3}$ There is a close relationship between the hypothalamic-pituitary-thyroid axis and the hypothalamicpituitary-ovarian axis. ${ }^{4}$

In areas with endemic goiter, iodine deficiency is the major cause of thyroid dysfunction. Infertility associated with thyroid dysfunction in these areas is not uncommon. ${ }^{5}$ Thyroid dysfunction which is quite prevalent in the population affects many organs including male and female gonads, interferes with human reproductive physiology, which reduces the likelihood of pregnancy and adversely affects pregnancy outcome, thus becoming relevant in the algorithm of reproductive dysfunction. ${ }^{6}$

Primary hypothyroidism is commonly associated with hyperprolactinemia due to the stimulatory effect of TRH on lactotrophs. ${ }^{7}$ A close interconnection is present between hypothyroidism and hyperprolactinemia. Failure to ovulate regularly in women of the reproductive age group may occur owing to hypothyroidism. ${ }^{8}$

\section{Materials and Methods}

Our study was a prospective cross-sectional study conducted in the Government Lala Ded Hospital of Government Medical College, Srinagar between May 2017 and January 2019.

After taking consent for the study, 50 married females with primary infertility were selected on OPD basis. After taking a
${ }^{1}$ Department of Gynecology and Obstetrics, Directorate of Health and Family Welfare, Srinagar, Jammu and Kashmir, India

${ }^{2}$ Department of Gynecology and Obstetrics, Government Medical College, Srinagar, Jammu and Kashmir, India

${ }^{3}$ Department of Surgery, Sher E Kashmir Institute of Medical Sciences, Soura, Srinagar, Jammu and Kashmir, India

Corresponding Author: Irfan N Mir, Department of Surgery, Sher E Kashmir Institute of Medical Sciences, Soura, Srinagar, Jammu and Kashmir, India, Phone: +91 9906460646, e-mail: irfanazir@gmail.com

How to cite this article: Akhter N, Khanday A, Mir IN. Hypothyroidism and Hyperprolactinemia as a Cause of Primary Infertility: A Single Center Study. Int J Infertil Fetal Med 2021;12(3):66-68.

Source of support: Nil

Conflict of interest: None

detailed history and complete general physical and gynecological checkup, blood samples were taken from patients for thyroid profile (T3, T4, TSH) and serum prolactin levels. This group was labeled as group I (cases).

At the same time, similar history, examination, and biochemical profiles of 50 age-matched fertile females were done for a similar profile, to act as a control. This group was labeled as group II (controls).

\section{Inclusion Criteria}

- Age 20-40 years.

- Married for a period of $>1$ year.

- Medically fit patients.

(c) Jaypee Brothers Medical Publishers. 2021 Open Access This article is distributed under the terms of the Creative Commons Attribution 4.0 International License (https://creativecommons.org/licenses/by-nc/4.0/), which permits unrestricted use, distribution, and non-commercial reproduction in any medium, provided you give appropriate credit to the original author(s) and the source, provide a link to the Creative Commons license, and indicate if changes were made. The Creative Commons Public Domain Dedication waiver (http://creativecommons.org/publicdomain/zero/1.0/) applies to the data made available in this article, unless otherwise stated. 


\section{Exclusion Criteria}

- Any gynecological disorder/deformity.

- Women with tubal blockage, pelvic inflammatory disease.

- Renal/cardiac disease.

- Previously detected hypothyroidism.

- On thyroxine medication/previous thyroid surgery.

- Abnormalities in semen analysis of partner.

- Patient on any long-term medication.

\section{Statistical Analysis}

Continuous variables were summarized as mean \pm SD and categorical variables were expressed as frequencies and percentages. Chi-square test or Fisher's test, whichever appropriate, was applied for data analysis. A $p$ value of $<0.05$ was considered statistically significant.

\section{Results}

In our study, the range of age of the patients in either group was between 20 years and 40 years of age. The mean age of patients in group I was 26.21 years, and that in group II was 25.63 years, respectively.

The average time since marriage in group I was found to be 1.67 years and that in group II was 1.78 years, respectively.

The rural-urban ratio of patients in group I was 23:27 and that in group II was 34:16, depicting a more frequency of infertility in the urban population when compared with the rural population.

The mean TSH level in group I was found to be $7.11 \pm 1.91$ and that in group II was found to be $3.28 \pm 2.11$ (Table 1).

The mean levels of serum prolactin in group I were $41.62 \pm$ 20.02 and that in group II were $22.36 \pm 15.61$, respectively (Table 1).

There was a high prevalence of hypothyroidism in group I when compared with group II. The mean T3 levels in group I were lower $(0.98 \pm 0.18)$ when compared with that in group II $(1.81 \pm$ $0.22)$, whereas T4 levels in group I were higher $(9.12 \pm 0.96)$ when compared with T4 levels in group II (5.16 \pm 0.71$)$ (Table 1).

\section{Discussion}

Infertility is a serious problem, more so in the present era of digitalization and urbanization, with busy life schedules, the problem of primary infertility seems to have magnified. The causes of primary infertility are manifold and can be due to problems with either of the partners or both. Among females, the cause of infertility may range from hormonal disorders, gynecological problems, medical causes, or intake of medication.

We have witnessed a huge increase in the number of female patients attending our OPD with primary infertility. We also noticed untreated hypothyroidism and hyperprolactinemia associated with many of these patients. With these findings in mind, we

Table 1: Thyroid profile and prolactin levels

\begin{tabular}{llrr}
\hline Biochemical test & $\begin{array}{l}\text { Normal } \\
\text { reference range }\end{array}$ & $\begin{array}{l}\text { Group I } \\
\text { (mean } \pm S D)\end{array}$ & \multicolumn{1}{l}{$\begin{array}{l}\text { Group II } \\
\text { (mean } \pm S D)\end{array}$} \\
\hline $\mathrm{T} 3(\mathrm{ng} / \mathrm{mL})$ & $0.9-1.95$ & $0.98 \pm 0.18$ & $1.81 \pm 0.22$ \\
$\mathrm{~T} 4(\mathrm{ng} / \mathrm{dL})$ & $4.4-12.5$ & $9.12 \pm 0.96$ & $5.16 \pm 0.71$ \\
$\mathrm{TSH}(\mu \mathrm{lU} / \mathrm{L})$ & $0.40-4.5$ & $7.11 \pm 1.91$ & $3.28 \pm 2.11$ \\
Prolactin $(\mathrm{ng} / \mathrm{mL})$ & $<25$ & $41.62 \pm 20.2$ & $22.36 \pm 15.6$ \\
\hline
\end{tabular}

decided to conduct a study to validate hypothyroidism and hyperprolactinemia as a cause of primary infertility, after ruling out other common causes of primary infertility.

In our study, we took samples from 50 patients for serum TSH, $\mathrm{T} 3, \mathrm{~T} 4$, and prolactin levels having primary infertility, after ruling out other causes of infertility in these patients. We also took a similar biochemical profile of 50 age-matched fertile females, to act as a control group.

The mean age of patients in group I was 26.21 years, and that in group II was 25.63 years, respectively. The average time since marriage in group I was found to be 1.67 years and that in group II was 1.78 years, respectively.

The rural-urban ratio of patients in group I was 23:27 and that in group II was 34:16. We found the prevalence of primary infertility to be more among the urban population when compared with the rural population. Although the sample size is small to validate the fact that primary infertility is more prevalent among the urban population.

Thyroid dysfunction is a condition known to reduce the likelihood of pregnancy and to adversely affect pregnancy outcomes. Data on the relationship between thyroid disorders and infertility remain scarce and the association with a particular cause of infertility has not been thoroughly analyzed. ${ }^{9}$

The mean TSH level in group I was found to be $7.11 \pm 1.91$ and that in group II was found to be $3.28 \pm 2.11$ (Table 1). The mean levels of serum prolactin in group I were $41.62 \pm 20.02$ and that in group II were $22.36 \pm 15.61$, respectively (Table 1 ).

In our study, we found that the TSH level is significantly higher among infertile cases than the control subjects. This finding is validated by the study done by Sridevi and Sandhya Rani. ${ }^{10}$

Prolactin inhibits follicle-stimulating hormone and the $\mathrm{GnRH}$, which are required for ovulation. When the level of prolactin secretion increases in the blood, it will inhibit ovulation, and this will result in infertility. ${ }^{11-13}$

Kumkum et al. in their study incidence of hypothyroidism in hyperprolactinemic women was $25.50 \%$ (13/51). So, a positive correlation of 1:4 was found between hypothyroidism and hyperprolactinemia. ${ }^{14}$

A study by Binita et al. found that $46.1 \%$ of infertile women with hypothyroidism had hyperprolactinemia. ${ }^{5}$

Turankar et al. reported increased levels of prolactin and TSH in infertile women compared with the control group. ${ }^{3}$

Characterized by high levels of serum TSH and low levels of thyroid hormones (T3 and T4) is high in infertile women when compared with normal fertile females. ${ }^{15}$

The mean prolactin level in hyperprolactinemic women in our study was $89.43 \pm 7.20 \mathrm{ng} / \mathrm{mL}$, similar findings were found by Mishra et al. ${ }^{16}$

\section{Conclusion}

This study showed significantly higher prolactin and TSH levels among the primary infertile female patients. A positive correlation is also found between serum prolactin and serum TSH level among the primary infertile group of patients. Therefore, for proper management of infertile cases, it may be necessary to look for thyroid dysfunction and treat it accordingly.

\section{Ethical Clearance}

Institutional ethical clearance. 


\section{References}

1. Micinsk $P$, Wielgus $E$, Wojcieszyn $M$, et al. Abnormal ovarian reserve test reflects thyroid dysfunction. Pol J Gyn Invest 2006;9(1):30-34.

2. AL-Mawajdeh IE. Correlation of thyroid hormones, gonadotropins and age in infertile women in the south of Jordan. Eur J Sci Res 2011;63:219-230.

3. Turankar S, Sonone K, Turankar A. Hyperprolactinaemia and its comparison with hypothyroidism in primary infertile women. J Clin Diagn Res 2013;7(5):794-796. DOI: 10.7860/JCDR/2013/4878.2941.

4. Frey KA, Patel KS. Initial evaluation and management of infertility by the primary care physicians. Mayo Clin Proc 2004;79(11):1439-1443. DOI: 10.4065/79.11.1439.

5. Binita G, Suprava P, Mainak C, et al. Correlation of prolactin and thyroid hormone concentration with menstrual patterns in infertile women. J Reprod Infertil 2009;10(3):207-212.

6. Southam AL. What to do with the normal infertile couple. Fertile Sterile 1960;11(6):543. DOI: 10.1016/S0015-0282(16)33969-3.

7. Patel SS, Bamigboye. Hyperprolactinemia. J Obstet Gynecol 2007;27(5):455-459. DOI: 10.1080/01443610701406125.

8. Bals-Pratsch M, De Geyter C, Muller T, et al. Episodic variations of prolactin, thyroid-stimulating hormone, luteinizing hormone, melatonin and cortisol in infertile women with subclinical hypothyroidism. Hum Reprod 1997;12(5):896-904. DOI: 10.1093/ humrep/12.5.896.
9. Freundl G, Godehardt E, Kern PA, et al. Estimated maximum failure rates of cycle monitors using daily conception probabilities in the menstrual cycle. Hum Reprod 2003;18(12):2628-2633. DOI: 10.1093/ humrep/deg488.

10. Sridevi N, Sandhya Rani M. Study of thyroid profile in infertile women. IOSR J Pharm Biol Sci 2015;10(3):57-61.

11. Koutras DA. Disturbances of menstruation in thyroid disease. Ann N Y Acad Sci 1997;816(1 Adolescent Gy):280-284. DOI: 10.1111/j.17496632.1997.tb52152.x.

12. Cramer DW, Sluss PM, Powers RD, et al. Serum prolactin and TSH in an in vitro fertilization population: is there a link between fertilization and thyroid function? J Assist Reprod Genet 2003;20(6):210. DOI: 10.1023/a:1024151210536.

13. Poppe K, Velkeniers B. Thyroid and infertility. Verh K Acad Geneeskd Belg 2002;64(6):389-399.

14. Kumkum A, Kaur J, Gupta S, et al. Hyperprolactinemia and its correlation with hypothyroidism in infertile woman. ObstetGynecol India 2005;56:68-71.

15. Valvekar U, Viswanathan S. Prevalence of hyperprolactinaemia and hypothyroidism in primary and secondary infertility women. J Med Sci Tech 2016;5(2):8-13.

16. Mishra R, Baveja R, Gupta V. Prolactin levels in infertility with menstrual irregularities. J Obstet Gynecol India 2002;52:40-43. 